\title{
GC-MS ANALYSIS AND ANTIMICROBIAL ACTIVITY \\ OF THE ESSENTIAL OIL OF TRUNK EXUDATES \\ OF Pistacia atlantica var. mutica
}

\author{
M. B. Habibi Najafi, ${ }^{1 *}$ R. Hajimohamadi Farimani, ${ }^{1}$ \\ J. Tavakoli, ${ }^{2}$ and S. Madayeni ${ }^{1}$
}

The genus Pistacia L. consists of 11 species, most of which are known to produce oleoresin. There are three kinds of pistachio in Iran, including $P$. vera, . atlantica, and $P$. khinjuk. Four subspecies or varieties have been identified for P. atlantica: cabulica, kurdica, mutica, and atlantica [1]. P. atlantica var. mutica is native to a number of temperate countries in Asia. In Iran, this plant grows in the central, western, and eastern regions. The oleoresin of $P$. atlantica var. mutica, known as "Turk terebinth gum," is used to make chewing gum in Iran. Mastic gum has been used in traditional medicine for various gastrointestinal disorders like gastralgia, dyspepsia, and peptic ulcer. Mastic gum has been reported to possess considerable in vitro antibacterial and antifungal activity. The total mastic extract without polymer might be effective in reducing Helicobacter pylori colonization as well as in the treatment of cutaneous leishmaniasis. This plant has also been used traditionally as an antiseptic and as a mouth freshener constituent [2]. The essential oil of $P$. atlantica var. mutica has also potential application as an antimicrobial agent in edible films $[2,3]$. The objectives of this study were to report the GC-MS analysis as well as the antibacterial activity of the essential oil of the trunk exudate from Pistacia atlantica var. mutica in order to evaluate its potential application as a natural food preservative.

GC-MS analysis has led to the identification of 21 components, listed in Table 1, representing $98.77 \%$ of total compounds. The major constituents of the essential oil of mastic gum were $\alpha$-pinene (54.97\%), myrcene (11.44\%), and limonene $(10.08 \%)$. A high content of $\alpha$-pinene was also found in the essential oil extracted from the gum of P. atlantica var. mutica [2], P. atlantica var. kurdica [4], P. lentiscus [5, 6], P. khinjuk [7], P. vera [8, 9], and P. terebinthus [10].

A comparison between the results of Delazar [2] and this work shows that $\alpha$-pinene is the main constituent respectively of both essential oils (70.00 and 54.97\%). On the other hand, no such similarity was found for the other components. The next two main components reported by Delazar are citral (5.72\%) and myrtenol (5.31\%), whereas our study showed that myrcene and limonene are ranked as the next two main components (11.44 and 10.08\%, respectively). Such variations are most likely related to the geographical origin, harvesting time, growing conditions, as well as extraction method [9].

Disc diffusion is one of the most common assays used in the evaluation of antibacterial activity of essential oils [11]. The results of antimicrobial activity of the essential oil and positive controls are presented in Table 2. The essential oil prevented bacterial growth of all studied bacteria except Pseudomonas aeruginosa. Pseudomonas aeruginosa is considered one of the most resistant bacteria against antimicrobial compounds [12]. Antimicrobial activity analyzed by the disc diffusion method showed that the oil resin of P. atlantica var. mutica was most active against Bacillus cereus, followed by Staphylococcus aureus and Escherichia coli $\mathrm{O} 157 \mathrm{H} 7$. These bacteria are the most common bacteria causing food-borne diseases.

With increasing essential oil concentration from 10 to $20 \mu \mathrm{L}$ per disc, antimicrobial activity was also increased. As can be seen, a concentration of 10 and $20 \mu \mathrm{L}$ of the essential oil per disc gives an inhibition zone greater than $7 \mathrm{~mm}$, which is considered as a reasonable limiting inhibition zone for an antibiotic [5]. In the case of Staphylococcus aureus, the clear zones of essential oil were smaller in comparison with those of ampicillin and streptomycin. However, the results of clear zones for Bacillus cereus and Escherichia coli were comparable to positive controls. Finally, gram-positive bacteria (Bacillus cereus and Staphylococcus aureus) were more susceptible to the essential oil as compared to gram-negative bacteria (Escherichia coli and Pseudomonas aeruginosa).

1) Department of Food Science and Technology, Ferdowsi University of Mashhad, Mashhad, Iran, e-mail: habibi@um.ac.ir; 2) Departmant of Food Science and Technology, Faculty of Agriculture, Jahrom University, P. O. Box 74137-66171, Jahrom, Iran. Published in Khimiya Prirodnykh Soedinenii, No. 2, March-April, 2014, pp. 324-326. Original article submitted October 15, 2012. 
TABLE 1. Chemical Composition of Essential Oil of the Trunk Exudates of Pistacia atlantica var. mutica

\begin{tabular}{|c|c|c|c|c|c|}
\hline Compound & KI & $\%$ & Compound & $\mathrm{KI}$ & $\%$ \\
\hline$\alpha$-Thujene & 932 & 1.4 & $Z$ - $\beta$-Ocimene & 1040 & 1.0 \\
\hline$\alpha$-Pinene & 943 & 55.0 & $E$ - $\beta$-Ocimene & 1052 & 0.6 \\
\hline Camphene & 955 & 0.7 & allo-Ocimene & 1132 & 0.1 \\
\hline Sabinene & 978 & 1.9 & trans-Verbenol & 1150 & 0.8 \\
\hline$\beta$-Pinene & 982 & 1.8 & Camphor & 1152 & 1.5 \\
\hline Myrcene & 995 & 11.4 & cis-Pinocamphone & 1177 & 0.3 \\
\hline$\alpha$-Phelandrene & 1008 & 1.5 & neo-Verbanol & 1186 & 0.3 \\
\hline$\alpha$-Terpinene & 1015 & 0.6 & $\alpha$-Copaene & 1379 & 0.7 \\
\hline$\rho$-Cymene & 1029 & 3.2 & $E$-Caryophyllene & 1422 & 2.6 \\
\hline Limonene & 1032 & 10.1 & Viridiflorol & 1598 & 0.6 \\
\hline 1,8 -Cineole & 1034 & 3.1 & & & \\
\hline
\end{tabular}

TABLE 2. The MIC Value of Essential Oil of the Trunk Exudates of Pistacia atlantica var. mutica

\begin{tabular}{l|c|c|c|c|c}
\hline \multirow{2}{*}{ Bacteria } & \multicolumn{2}{|c|}{ Pure essence } & \multirow{2}{*}{ MIC (ppm) } & \multicolumn{2}{|c}{ Positive control } \\
& $10 \mu \mathrm{L} /$ disk & $20 \mu \mathrm{L} /$ disk & & ampicillin & streptomycin \\
\hline \multirow{2}{*}{ Bacillus cereus ATCC 10876 } & 11.8 & 14.1 & 1000 & not visible & 15.3 \\
Staphylococcus aureus subsp. Aureus ATCC 25923 & 11.0 & 13.0 & 4000 & 23.8 & 20.8 \\
Escherichia coli O157 H7 & 8.4 & 11.4 & $>8000$ & 8.5 & 14.3 \\
Pseudomonas aeruginosa ATCC 27853 & Not visible & Not visible & $>8000$ & Not visible & 10.3 \\
\hline
\end{tabular}

The radius of the zone of inhibition was measured in $\mathrm{mm}$.

This is in agreement with other reports claiming that plant extracts are more active against gram-positive than gram-negative bacteria [11]. The inhibition activity of the oil can be attributed to the high content of $\alpha$-pinene. It has been reported that $\alpha$-pinene possessed antimicrobial activity $[4,8,13]$.

Raw Material and Essential Oil Extraction. The resin of $P$. atlantica var. mutica (mastic gum) was obtained from the City of Marvdasht in Fars Province, Iran. Mastic gum was kept in the refrigerator $\left(4^{\circ} \mathrm{C}\right)$ until the day of experiment. The essential oil was extracted from the resin by hydrodistillation using a Clevenger apparatus for $3 \mathrm{~h}$ to give a pale yellow oil. The essential oil was stored in the dark at $4^{\circ} \mathrm{C}$ in an airtight container [2].

Identification of Oil Components. The components of volatile oil from the resin of P. atlantica var. mutica were identified using gas chromatography (GC) and gas chromatography-mass spectrometric (GC-MS) apparatus. The gas chromatograph (GC) was a Shimadzu GC-17 equipped with an FID detector and a fused-silica column (HP-5MS, $30 \mathrm{~m} \times 0.25 \mathrm{~mm}$ i.d., film thickness $0.25 \mu \mathrm{m}$ ). The operating conditions were: oven temperature $60-210^{\circ} \mathrm{C}$ raised at the rate of $3^{\circ} \mathrm{C} / \mathrm{min}$ then $210-240^{\circ} \mathrm{C}$ at the rate of $20^{\circ} \mathrm{C} / \mathrm{min}$; injector temperature $280^{\circ} \mathrm{C}$, split ratio $1: 10$, carrier gas He; detector temperature $280^{\circ} \mathrm{C}$.

The GC-MS apparatus was a Varian GC-MS spectrometer consisting of a Varian star 3400 gas chromatograph equipped with a fused-silica column (HP-5, $30 \mathrm{~m} \times 0.25 \mathrm{~mm}$ i.d, film thickness $0.25 \mu \mathrm{m}$; J\&W Scientific Inc.), interfaced with a mass spectrometric detector (Varian Saturn 3). The operating conditions were: oven temperature $60-280^{\circ} \mathrm{C}$ raised at the rate of $3^{\circ} \mathrm{C} / \mathrm{min}$; injector temperature $280^{\circ} \mathrm{C}$; injector mode: split injection; carrier gas $\mathrm{He}$; flow rate $0.5 \mathrm{~mL} / \mathrm{min}$; mass spectra: electronic impact (EI), ionization potential $70 \mathrm{eV}$, ion source temperature $250^{\circ} \mathrm{C}$, ionization current $1000 \mu \mathrm{A}$, resolution 1000 , and mass range 40-300 amu.

The oil components were identified from their retention indices (RI) obtained with reference to the $n$-alkane series (Sigma, UK) on an HP-5 column; mass spectra were obtained by comparison with those of authentic samples from mass spectra and fragmentation patterns reported in the literature, as well as by computer matching with the MS-data bank (Saturn version 4). Quantification of the relative amounts of the individual component was performed according to the area percentage method without consideration of a calibration factor.

Bacterial Strains. The gram-positive bacteria (Staphylococcus aureus ATCC25923 and Bacillus cereus ATCC10876) and gram-negative bacteria (Escherichia coli $\mathrm{O} 157 \mathrm{H} 7$ and Pseudomonas aeruginosa ATCC 27853) were obtained from the Faculty of Veterinary Medicine, Ferdowsi University of Mashhad, Mashhad, Iran. 
Determination of Antibacterial Activity. Agar Disc Diffusion Method. The bacteria were first incubated at $37^{\circ} \mathrm{C}$ for $18 \mathrm{~h}$ in nutrient agar slant. The microbial strains were diluted to an optical density of $0.5 \mathrm{McFarland}$ standard at $\mathrm{A}_{530}$ with sterile Ringer solution. Then $1 \mathrm{~mL}$ of suspension was transferred to a sterile tube with $9 \mathrm{~mL}$ Ringer solution to obtain $1.5 \times 10^{7} \mathrm{cfu} / \mathrm{mL}$ microbial suspension. Mueller-Hinton agar was then poured into the Petri dishes. After solidification, $0.1 \mathrm{~mL}$ of inoculum was spread uniformly and dried for $5 \mathrm{~min}$. Subsequently, the sterilized blank paper disks of $6 \mathrm{~mm}$ diameter were placed onto the agar plates, which had previously been inoculated with the above organisms. Ten to $20 \mu \mathrm{L}$ of essential oil was added to each disk. In addition, ampicillin (10 $\mu \mathrm{g}$ per disk) and streptomycin (10 $\mu \mathrm{g}$ per disk) (Padtan-Teb, Iran) were used as positive controls. Afterwards, the plates combined with the disks were kept at $4^{\circ} \mathrm{C}$ for $2 \mathrm{~h}$, followed by incubation at $37^{\circ} \mathrm{C}$ for $24 \mathrm{~h}$. After $24 \mathrm{~h}$, the inhibition zones appearing around the disks were measured and recorded in millimeters [9].

Determination of Minimal Inhibitory Concentration (MIC). Bacterial strains were cultured overnight (12-18 h) at $37^{\circ} \mathrm{C}$ in nutrient agar slant. The microbial strains were diluted to an optical density of $0.5 \mathrm{McFarland}$ standard at $\mathrm{A}_{530}$ with sterile Ringer solution. Dilution was made until a microbial suspension of $1.5 \times 10^{6} \mathrm{cfu} / \mathrm{mL}$ was obtained. A $0.5 \mathrm{~mL}$ portion of the suspension was delivered to each tube containing sterile Mueller-Hinton broth (MHB) supplemented with Tween 80 detergent (final concentration $0.5 \%(\mathrm{v} / \mathrm{v})$ ). Then essential oil of different amounts ranging from 2.5 to $80 \mu \mathrm{L}$ was added. One growth control (MHB + Tween 80) and one sterility control (MHB + Tween $80+$ test oil) were also used. The test tubes were incubated under normal atmospheric conditions at $37^{\circ} \mathrm{C}$. After $24 \mathrm{~h}$ incubation, serial dilution in Ringer solution was made, and Petri dishes containing Mueller-Hinton agar were inoculated and incubated in $37^{\circ} \mathrm{C}$ for $24 \mathrm{~h}$. The MIC was expressed as the lowest concentration of the essential oil that inhibited visible growth [9].

\section{REFERENCES}

1. R. Farhoosh, J. Tavakoli, and M. H. Haddad Khodaparast, J. Am. Oil Chem. Soc., 85, 723 (2008).

2. A. Delazar, R. G. Reid, and S. D. Sarker, Chem. Nat. Compd., 40, 24, (2004).

3. M. Taran, M. Mohebali, and J. Esmaeli, Iran. J. Publ. Health, 39 (1), 36 (2010).

4. $\quad$ M. S. Sharifi and S. L. Hazell, J. Pharm. Sci. Res., 3 (8), 1364 (2011).

5. P. Mgiatis, E. Melliou, A. Skaltounis, I. B. Chinou, and S. Mitaku, Planta Med., 65, 749 (1999).

6. V. Castola, A. Bighelli, and J. Casanova, Biochem. Syst. Ecol., 28, 79 (2000).

7. P. Monaco, L. Previtera, and L. Mangoni, Phytochemistry, 21, 2408 (1982).

8. M. Ramezani, M. Khaje-Karamoddin, and V. Karimi-Fard, Pharm. Biol., 42 (7), 488 (2004).

9. M. H. Alma, S. Nitz, H. Kollmannsberger, M. Digrak, F. T. Efe, and N. Yilmaz, J. Agric. Food Chem., 52, 3911 (2004).

10. M. Shahid, M. Shafiq, and S. Abdul, Sci. Int., 6, 167 (1994).

11. B. R. Ghalem and B. Mohamed, Afr. J. Pharm. Pharmacol., 3 (3), 87 (2009).

12. G. F. Brooks, K. C. Carroll, J. S. Butel, S. A. Morse, Jawetz, and Melnick, Adelberg's Medical Microbiology, $24^{\text {th }}$ Edition, McGraw-Hill, 2007.

13. K. Knobloch, A. Pauli, B. Iberl, N. Weis, and H. Weigand, J. Essent. Oil Res., 1, 119 (1989). 